\author{
Abstracta Iranica \\ Abstracta Iranica Revue bibliographique pour le domaine irano-aryen \\ Volume 42-43 | 2021 \\ Comptes rendus des publications de 2019-2020
}

\title{
Antonio Panaino. Old Iranian Cosmography: Debates and Perspectives
}

Alessia Zubani

\section{OpenEdition}

1 Journals

\section{Édition électronique}

URL : https://journals.openedition.org/abstractairanica/54316

DOI : 10.4000/abstractairanica.54316

ISSN : 1961-960X

Éditeur :

CNRS (UMR 7528 Mondes iraniens et indiens), Éditions de l'IFRI

\section{Référence électronique}

Alessia Zubani, «Antonio Panaino. Old Iranian Cosmography: Debates and Perspectives », Abstracta Iranica [En ligne], Volume 42-43 | 2021, document 3, mis en ligne le 30 décembre 2021, consulté le 30 décembre 2022. URL : http://journals.openedition.org/abstractairanica/54316 ; DOI : https://doi.org/ $10.4000 /$ abstractairanica. 54316

Ce document a été généré automatiquement le 30 décembre 2022.

Tous droits réservés 


\title{
Antonio Panaino. Old Iranian Cosmography: Debates and Perspectives
}

\author{
Alessia Zubani
}

\section{RÉFÉRENCE}

Antonio Panaino. Old Iranian Cosmography: Debates and Perspectives. Milano - Udine :

Mimesis, 2019, p. 148 (Iranica et Mediterranea)

1 Ce livre, résultat des recherches menées dans le cadre du projet "Visualisation of the Heavens before 1700 as a concern of history of science" au sein du Max Planck Institute of Berlin, offre une étude synthétique sur la question de la cosmographie et uranographie iranienne, notamment mazdéenne. L'A. se penche sur nombre de questions astronomiques et astrologiques en explorant leur développement tout au long de l'histoire de l'Iran préislamique et des premiers siècles de la domination islamique. L'étude veut également mettre en lumière l'existence de relations interculturelles et interlinguistiques entre le monde iranien ancien et les sociétés mésopotamiennes, indiennes, gréco-romaines, centrasiatiques et chinoises.

Le volume se compose de quatre sections principales. Après une brève introduction ( $\mathrm{p}$. 9-10) et un premier chapitre qui fournit une contextualisation historique générale (pp. 11-18), l'A. se penche sur des problématiques d'ordre historiographique et méthodologique et sur les spécificités de la cosmographie dans le monde iranien ancien (p. 19-47). Le troisième chapitre (p. 49-63), consacré aux époques hellénistique et parthe, explore en particulier la question de la démonisation des planètes, le mouvement planétaire et l'introduction de deux planètes fictives (le "Soleil noir ", mihr i tamig, et la «Lune noire ", māh i tamīg) pour expliquer le phénomène d'éclipse. Au chapitre suivant (p. 65-106), l'A. considère la période sassanide et postsassanide, en discutant les sources pertinentes (textes moyen-perses, tables royales astronomiques) et en mettant en relief certains sujets majeurs, tels que les doctrines 
des manoirs lunaires et de grandes conjonctions. Une vaste bibliographie (p. 111-140) conclut l'étude.

\section{AUTEURS}

ALESSIA ZUBANI

Labex HaStec, EPHE-PSL 